terms have much to recommend them since neither qualifies genesis or palaeogeography. However, they do suggest a relative state of 'normality' which is impossible to assess.

Strahan and Cantrill',5 used the terms 'littoral' and 'normal' deposits. The former conveys a palaeoecological concept which is difficult to prove for the Rhaetic and Lias and which is definitely out of place for the continental Keuper. The latter fails on the same count as does Moore's 'normal'.

'Near-shore' and 'off-shore' facies have been introduced more recently ${ }^{6}$. These terms suggest a palaeogeographical relationship which cannot be proved at all times. Socalled 'near-shore' facies may develop around an inlying mass of older strata projecting above the depositional interface but not necessarily projecting above the surface of the body of water in which deposition occurred.

Because the inferences of the terms mentioned here cannot be verified, are ambiguous or are misleading, new terms must be introduced. Terms conveying purely geometrical relationships must be considered. These terms should best be defined in relation to the distribution of the facies on one depositional interface. Two possible terms are: peripheral and periphractic for the coarse- and fine-grained facies, respectively. These terms are cumbersome and almost homophones and therefore do not seem practical. 'Proximal' and 'distal' are more familiar and like peripheral and periphractic do not have any palaeoecological or palaeogeographical connotations.

'Proximal' facies have accumulated along the periphery of one depositional interface and are closely associated with masses of older rock projecting above the interface immaterial as to whether these masses occur as submerged reefs or land. The sediments in this facies are on the whole coarse-grained, often containing much rudaceous material. 'Distal' facies are those general to the parts of the same depositional interface at some distance from the margins of the interface. This facies is generally fine-grained.

Regarding the two main facies of the Keuper to Lias strata of the Bristol Channel region, I should like to propose that the term 'proximal' be used for the generally coarse-grained facies which has developed close to the masses of older rock projecting above the depositional interface, and 'distal' for the generally fine-grained facies which has developed at a distance from these masses.

Part of this work was done while I was in the Department of Geology, University College, Cardiff, and while I was holding a D.S.I.R. research scholarship.

Department of Geology,

E. C. Willey

University of Cambridge. ${ }^{1}$ Buckland, W., and Conybeare, W. D., Trans. Geol. Soc. Lond. (second

¿De la Beche, H. T., Mem. Geol. Surv. Gt. Brit., 1, 1 (1846).

'Moore, C., Quart. J. Geol. Soc. Lond., 23, 449 (1867).

Strahan, A., and Cantrill, T. C., The Geology of the South Wales Coalfield, Part 3, The Country around Cardiff, Mem. Geol. Surv. U.R. (1902).

${ }^{5}$ Strahan, A., and Cantrill, T. C., The Geology of the South Wales Coalfield,

- Hallam, A., Phil. Trans. Roy. Soc., B, 243, 1 (1960).

\section{Origin of Pillow Structure in Lavas}

SINCE pillow structures were first observed, their origin has been controversial and diverse suggestions have been put forward (for excellent summaries see refs. 1 and 2). Despite a number of fairly recent papers favouring a sub-aerial origin, the consensus of opinion falls heavily on an aqueous environment for pillow formation. This conclusion is based mainly on field association, and also on the idea that the pillows are akin to emulsions, with the magma dispersed in the aqueous phase ${ }^{1,3,4}$. Fuller ${ }^{3}$, and Snyder and Fraser ${ }^{4}$, briefly mention the role of surface tension. Fuller suggests that "As in all emulsions, the dispersal of the fluid with the higher surface tension may have been attained either by the agitation of the two phasos or by its entry as detached units". Snyder and Fraser, however, suggested that "some force akin to surface tension is instrumental in the formation of the Unalaskan pillows".

I suggest that the two major factors in the formation of pillows are: (i) the surface tension of the molten magma; (ii) the density of the medium in which the pillows develop.

When lava erupts into any medium, it will tend to reduce its surface area to a minimum, that is, form spheres. If the density of the magma equalled that of the medium, a sphere would form and grow indefinitely, provided magma continued to be supplied. As it grew, the force required to enlarge the sphere $(P)$ would decrease, because $P=2 \gamma / r$, where $\gamma=$ surface tension and $r=$ radius of the sphere. However, where the density contrast between medium and magma is great, gravitational forces would prevent growth of a sphere and cause the magma to spread out as a sheet. The surface tension of basaltic magma in air is probably in the region of 300 dynes/cm (ref. 5) and this force is insufficient to maintain a sphere in air. However, in water the situation is much more favourable because the density contrast between magma and medium is reduced from, say, $1,500 / 1$ in air to $1 \cdot 5 / 1$ in water. The contrast is still further reduced if the magma enters unconsolidated mud or tuff. The fact that many of the best developed pillows have formed in muds and unconsolidated waterladen tuffs supports this conclusion ${ }^{4,6}$. It is likely that most of these pillows are essentially intrusive in that they never reach the main sediment-water interface.

Gravitational forces tend to put an upper limit on the size of stable spheres, dopending on the density contrast, and near this limit pillows tend to neck or bud. In some cases, the chilled skin developing on the pillow may retard or prevent further pillow growth, as was pointed out by Rittmann $^{6}$. However, chilled skins may thicken quite slowly if convection in the surrounding poorly-conducting water is inhibited, as it might be in mud or tuff, and it is clear that many pillows and their skins remain at sufficiently low viscosity to undergo considerable plastic deformation due to accumulating overburden. Thus the effect of the ehilled skin on growth may often be small.

In conditions of fairly rapid cooling, a high rate of lava omission would presumably favour formation of large pillows.

Several other factors are likely to affect the tendency of a magma to form pillows. For example, a relatively high viscosity would make the surface tension effect negligible, and this, combined with the effect of the high viscosity on the explosiveness of the magmas, is probably why there are only a few examples known of rhyolitic or andesitic pillows.

The size of the orifice through which the magma emerges must also be an important factor, and it seems reasonable that relatively small orifices (for example, cracks on the edges and surface of a flow) will favour pillow development.

Department of Geology,

University of Tasmania,

Hobart, Australia.

${ }^{1}$ Lewis, J. V., Bull. Geol. Soc. Amer., 25, 591 (1914).

${ }^{2}$ Snyder, G. L., and F'raser, G. D., U.S. Geol. Surv. Prof. Paper 454 C (1963).

${ }^{3}$ Fuller, R. E., Bull. Geol. Soc. Amer., 51, 2022 (1940).

- Snyder, G. L., and Fraser, G. D., U.S. Geol. Surv. Prof. Paper 454B (1963).

5 Morey, G. W., The Properties of Glass, 519 (Reinhold Pub. Corp., New York, 1954). ${ }^{6}$ Rittmann, A., Volcanoes and their Activity, 305 (John Wiley and Sons, New
York, 1962).

\section{A Proposed Correlation between Elastic Strain Rebound Increments and Isostatic Gravity Anomalies}

ELASTIC strain rebound increments have bcen extensively considered by Benioff and others ${ }^{1-6}$. The results of their investigations indicate that strain rebound increments vary from region to region. Their characteristics are 